\title{
Comparative Evaluation in Linear Dimensions among Various Interocclusal Recording Materials at Various Mounting Times:
}

\section{An In Vitro Study}

\author{
Anu Sharma ${ }^{1}$, Tarun Kalra ${ }^{2}$, Shailesh Jain ${ }^{3}$, Khurshid Mattoo ${ }^{4}$, Ramandeep Kaur ${ }^{5}$
}

\begin{abstract}
Aim: This in vitro study aims to investigate the longest possible dimensionally stable interocclusal recording materials among polyvinylsiloxane (PVS), polyether, zinc oxide eugenol, and wax, over a period of 1, 24, 48, 72, and 168 hours.

Materials and methods: A stainless steel metal die with known dimensions was used to fabricate 30 samples for 4 different groups (materials) with each group having 5 different subgroups (time interval). Linear dimensional changes were determined by observing the amount of change at six different intersecting fixed points on each sample. While the dimensional change was measured in the percentage using mean and standard deviations, the nature of differences between the materials was determined using one-way analysis of variance (ANOVA). To find which specific groups were significantly different from each other, a Tukey HSD (post hoc) test was employed. The significance of differences was determined at three different levels of $p$ value ( $\geq 0.05=$ not significant, $\leq 0.05=$ significant, and $\leq 0.001=$ highly significant).

Results: Dimensional changes were detected in bite wax (Aluwax) from as early as 1 hour, which relatively increased significantly. Among all materials, PVS (O bite) showed the least dimensional changes at all observed intervals closely followed by polyether (Ramitec) till the 3rd day of observation, differences between the two, however, were significant at 1 hour while being highly significant at remaining time intervals. Both zinc oxide eugenol (Bosworth) and bite registration wax (Aluwax) showed highly significant differences than the original dimensions and with both elastomers.

Conclusion: The study concludes that for a delay of up to 7 days, polyvinyl siloxane interocclusal records show the least changes while for a delay of up to 3 days either polyvinyl siloxane or polyether-based interocclusal material can be used.

Clinical significance: Polyvinyl siloxane is the material of choice for making interocclusal records presently. There should, however, be no delay in mounting the casts on the articulator irrespective of any type of material used to make an interocclusal record.

Keywords: Articulator, Elastomer, Interocclusal records, Mounting, Programming articulator.

World Journal of Dentistry (2020): 10.5005/jp-journals-10015-1776
\end{abstract}

\section{INTRODUCTION}

Natural dentition provides a hard tissue contact of the mandible to the cranium, while the mandible is connected through a bilateral diarthrodial soft tissue (articular disk) contact. The effectiveness of mandible as a functional lever for mastication is dependent on a uniform and even tooth contact with each other. Occlusal restorations not only require knowledge of the stomatognathic system, ${ }^{1}$ but more importantly the application of material science while choosing an interocclusal recording material (IRM). In occlusal rehabilitations, the accuracy of teeth contacting each other in a biocompatible position relies on how well a centric relation record has been recorded and then transferred. The accuracy of the transfer becomes more significant for fixed restorations including implants. ${ }^{2}$ Although multiple factors contribute to restoration accuracy, the choice of selecting an IRM is mainly based on its ability to mount casts precisely to the articulator. ${ }^{3}$ Even though an articulator simulates the patient's mandibular movements as closely as possible, ${ }^{4}$ a lot depends upon the clinician to minimize errors during the making of interocclusal records. ${ }^{5} \mathrm{~A}$ principled approach includes making the interocclusal record at the correct occlusal vertical dimensions and centric relation position, using dimensionally stable and accurate recording material, and selecting the most appropriate method of mandibular guidance. ${ }^{6}$ Interocclusal recording material needs dimensional stability during

\footnotetext{
1,2Department of Prosthodontics, Bhojia Dental College and Hospital, Baddi, Himachal Pradesh, India

${ }^{3}$ Department of Prosthodontics, School of Dental Sciences, Sharda University, Greater Noida, Uttar Pradesh, India

${ }^{4}$ Department of Prosthetic Dental Sciences, College of Dentistry, Jazan University, Kingdom of Saudi Arabia

${ }^{5}$ Private Dental Practice, Chandigarh, India
}

Corresponding Author: Khurshid Mattoo, Department of Prosthetic Dental Sciences, College of Dentistry, Jazan University, Kingdom of Saudi Arabia, Phone: +966595086078, e-mail: drkamattoo@rediffmail. com

How to cite this article: Sharma A, Kalra T, Jain S, et al. Comparative Evaluation in Linear Dimensions among Various Interocclusal Recording Materials at Various Mounting Times: An In Vitro Study. World J Dent 2020;11(6):462-467.

Source of support: Nil

Conflict of interest: None

recording, during transfer, and during transport from the clinics to the scheduled laboratory. Underlying denture bases (self or heat cure $^{7}$ and disinfecting agents ${ }^{8}$ further contribute to dimensional variations of IRM in removable prosthodontics. Routine transfer of patients work from a dental clinic to a dental laboratory has been currently affected because of frequent and abrupt shutdowns 
that are associated with controlling the spread of the current pandemic of COVID-19 diseases. While the early response of dental associations advised practitioners to limit dental practice to urgent care, a study in China reported a decrease in reporting of urgent dental treatments but an increase in the proportion of regular dental and oral infections. ${ }^{9}$ Closure of international and national flights, couriers, and other postal means have led to delays which compromise treatment accuracy, especially in the case of use of interocclusal record-related procedures. Seeing the present situations and the demands of the clinical practitioner, many companies have claimed their product to be dimensionally stable for an extended period. ${ }^{10}$ This study in the present context of the pandemic was therefore aimed to evaluate as well as compare the dimensional changes of four commonly used IRMs [polyether, bite registration wax, polyvinylsiloxane (PVS), and zinc oxide eugenol] used commonly in different prosthodontic applications. The intervals at which the material was examined for dimensional stability correlated to the most common clinical occurrences ( 1 hour, 1 day, 2 days, 3 days, and 7 days) in the present pandemic situation. A period of 7 days was decided to be a maximum period for an interocclusal record to be either transported or preserved for a patient. The objective of the study was to investigate the ability of the material to withstand changes for a longer period that would accommodate unintentional clinical delays as a result of the present situation.

\section{Materials and Methods}

\section{Study Design}

\section{Ethics}

The present study was conducted at the Department of Prosthodontics of Bhojia Dental College, Himachal Pradesh University during the first two quarters of the year 2020. The study proposal was duly approved by the ethical committee of the institute which is affiliated to the deanship of the research division of the university (Approval No BDC/BUDH/SF/24613) which conducts its studies following standards as laid down in the Helsinki declaration. ${ }^{11}$

\section{Fabrication of the Master Die}

A metal die fabricated from a grade 1.4529 austenitic (1925hMo) stainless steel ( $20 \%$ chromium, $25 \%$ nickel, $6 \%$ molybdenum super-austenitic stainless steel) was designed according to the American dental association specification no 19, for testing elastomeric materials (Fig. 1). ${ }^{12}$ The metal die block was ruled into millimeter-scale with three horizontal inscribed lines (Y-line, medium $\mathrm{X}$-line, and a Z-line) and two vertical lines intersecting each other at six different places. All lines were separated by equal distances. Four IRMs such as PVS (O-Bite, DMG, USA), polyether (Ramitec, 3M ESPE, AG Dental Products, Germany), zinc oxide eugenol ( $\mathrm{ZnOE})$ (Bosworth plastopaste, Germany), and bite registration wax with aluminum filling (arched) (Aluwax, Michigan, USA) were procured and for each material the number of required sample was estimated to be 30 disk specimens for each testing subgroups $(1,24,48,72$, and 168 hours). All samples were removed from their storage containers on the day of testing and after measuring desired changes, the samples were discarded.

\section{Sample Size, Grouping, and Testing}

For each material type, the manipulation was done as per the manufacturer's instructions following recommended materials and methods. All samples were prepared at room temperature with a normal relative humidity range (30-50\%). For preparing elastomeric (PVS and polyether) samples, the die was covered with a thick glass slab (4/4 inch) using hand pressure initially ( 5 seconds) and once the metal ring emerges, a weight of $500 \mathrm{~g}$ was applied to remove the flash. The entire assembly of the mold, die, and weights were then submerged in a water bath $\left(35^{\circ} \mathrm{C}\right)$ till the material would set. This was followed by removing the metal ring from the die followed by finishing the sample using a sharp knife (Bard parker). For preparing samples for bite registration wax, the material was softened in a warm water bath $\left(40-45^{\circ} \mathrm{C}\right)$ for 5 minutes and then placed in the mold with the help of a hydraulic syringe. While polyether and ZnOE were mixed with hands, an automix technique was used for PVS bite registration material. One hundred and fifty specimens (30 extra specimens for replacements if required) for each material [group (Gp) I-PVS, Gp II-polyether, Gp III-ZnOE, and Gp IVWax] were then analyzed within their respective subgroups (1, 24, 48,72 , and 168 hours) based on time intervals. All samples were stored using ideal conditions until testing (room temperature, waterproof container, and no exposure to direct sunlight). Each sample in the form of a $3 \times 0.3 \mathrm{~cm}$ disk was evaluated for the recording of horizontal and vertical lines inscripted in the die. For considering the dimensional stability of each specimen, the linear
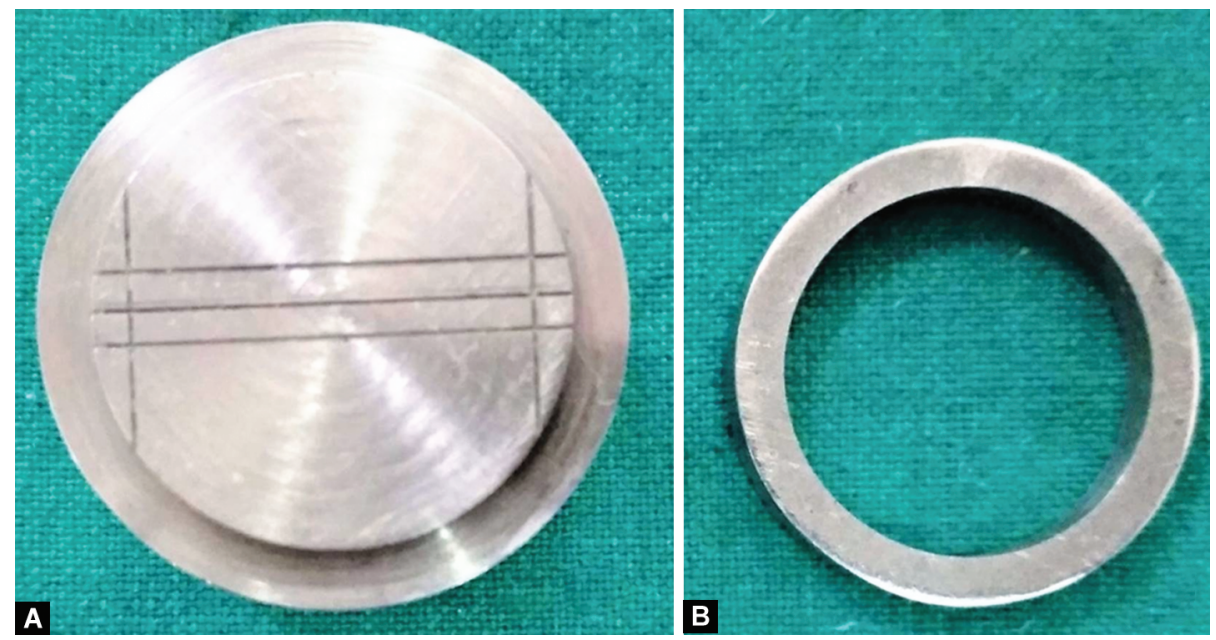

Figs $1 \mathrm{~A}$ and B: Stainless steel die with three horizontal lines traversed by two vertical lines at six different points 
distance between the parallel lines was measured at six different intersecting fixed points using a universal measuring microscope with a magnification of $10 \times$ (Fig. 2). The mean of these six different readings was considered for statistical analysis of that particular specimen. The mean distance between the lines of each sample was compared to the corresponding measured distance in the stainless steel die. The change in the dimension was calculated by using the mathematical formula for measuring the dimensional change in percentage [Dimensional change $\%=(X-Y) / X \times 100$ ] where $X$ is the standard measurement $(\mathrm{mm})$ between the line $A$ and $B$ in the die and $Y$ is a similar measurement at the sample.

\section{Measuring, Recording, and Statistical Analysis}

For each material, measures for 30 specimens were done in each subgroup (interval of time). Descriptive analysis included measures of central tendency and dispersion while inferential analysis to determine the significance of differences between the group and within groups was calculated using a one-way analysis of variance (ANOVA) test. A Tukey HSD (post hoc) test was performed to find out which specific groups' means (compared with each other) were significantly different from each other and at what level. Various levels of significance were kept at a $p$ value of $\geq 0.05$ as not significant, $\leq 0.05$ as significant, and $\leq 0.001$ as highly significant.

\section{Results}

A total of 600 specimens ( 30 specimens in 5 different time interval subgroups of 4 groups) were used to collect and evaluate the results. Deviation from normal (actual dimensions of the die) was calculated at six different static intersecting points (between horizontal and vertical lines) on the sample and a mean of these readings was chosen for each sample. Within each time interval, mean and standard deviations were recorded as represented in

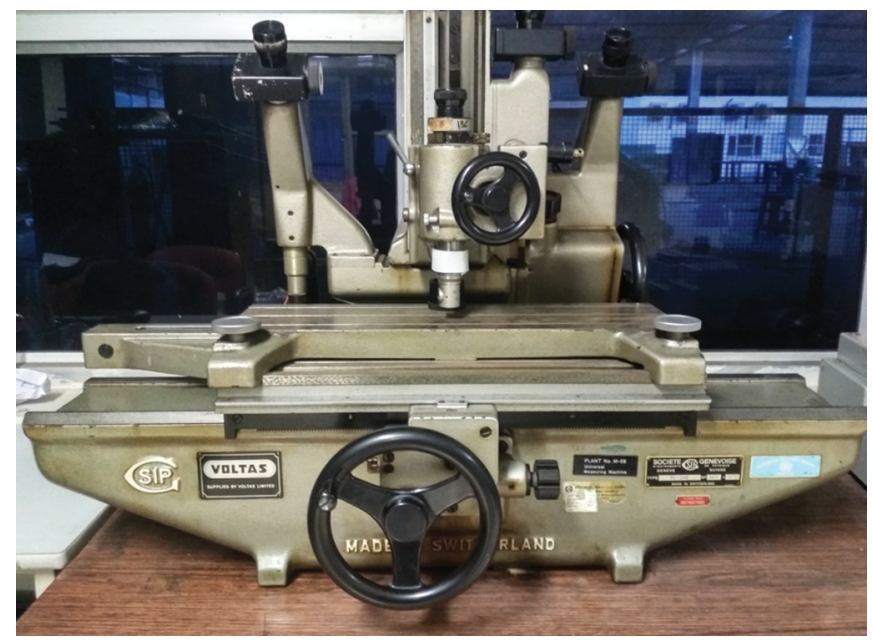

Fig. 2: Universal measuring machine
Table 1. The samples of group I (PVS) showed linear changes at 1 hour $(M=0.208)$, 24 hours $(M=0.474), 48$ hours $(M=0.662), 72$ hours $(M=0.783)$, and 168 hours $(M=1.00)$, respectively. Similarly, samples of Gp II (polyether) with means of 0.217 (1 hour), 0.486 ( 24 hours), 0.690 (48 hours), 0.796 (72 hours), and 1.268 (168 hours) and samples of Gp III ( $\mathrm{ZnOE}$ ) with means of 0.47 ( 1 hour), 0.633 (24 hours), 0.772 (48 hours), 1.08 (72 hours), and 1.67 (168 hours) demonstrated respective linear changes in dimensions. Among the samples of all the groups, the PVS samples demonstrated the least changes at all intervals of time $(M=0.208$ at 1 hour, 0.474 after 24 hours, 0.662 after 48 hours, 0.78 after 72 hours, and 1 after 168 hours). Maximum changes (between 50 and $60 \%$ or above) in all materials occurred within the first 3 days with Gp IV (wax) continually showing a steady increase till 7 days $(M=0.608$ at 1 hour to 1.885 after 7 days). The differences in the means between four independent (unrelated) groups are presented in Table 2. One-way ANOVA test shows the differences between the groups and within the group were statistically highly significant at a level of $p$ value of $<0.001$. Table 3 presents the degree of differences at various levels of comparisons between materials subgroups. It represents where the differences lie in the results. For all materials, the differences were significant, although the degree of significance varied ( $p<0.05=$ significant and $p<0.001=$ highly significant). The only comparative difference between polyether $(m=0.008)$ was considered as significant that too only for sample after 1 hour, while all others were highly sensitive differences.

With each time interval, there was a substantial and significant change in the linear dimensions of all the four materials studied. Polyvinylsiloxane showed the least change in dimensions at all intervals while Aluwax showed the highest changes at all intervals. Polyether showed changes that were competitive to PVS to 72 hours but showed rapid deterioration in dimensions after that. None of the material can claim to be dimensionally stable at the investigated intervals of time. However, based on the results of this study, PVS should be preferred over polyether, $\mathrm{ZnOE}$, and Aluwax in the same order of preference.

\section{Discussion}

This in vitro study of various IRMs was conducted to compare the dimensional changes of four different recording materials over a period of five different intervals of time. The primary purpose of IRMs is to transfer the determined interocclusal relationship of the patient's jaws. ${ }^{13}$ This transfer gains more importance because the diagnosis of a pathogenic occlusion is dependent upon it being clinically accurate and stable. While clinical accuracy largely depends on clinical variables, including the skill of the clinician or the neuromuscular ability of the patient, the stability of the interocclusal record depends largely on its inherent properties. It must be therefore overemphasized that duplication of occlusal relations and their transfer in the form of interocclusal records should have high standards to overcome materials' inherent

Table 1: Comparative differences in means $(n=30)$ between various groups at different intervals of testing time

\begin{tabular}{lcccc}
\hline Time interval & Group I $(n=30)$ & Group II $(n=30)$ & Group III $(n=30)$ & Group IV $(n=30)$ \\
\hline 1 hour $(n=30)$ & $0.2089 \pm 0.002$ & $0.217 \pm 0.007$ & $0.47 \pm 0.01$ & $0.6082 \pm 0.016$ \\
24 hours $(n=30)$ & $0.4745 \pm 0.007$ & $0.4864 \pm 0.008$ & $0.6339 \pm 0.013$ & $0.9446 \pm 0.007$ \\
48 hours $(n=30)$ & $0.6623 \pm 0.012$ & $0.6904 \pm 0.011$ & $0.7720 \pm 0.011$ & $1.2155 \pm 0.015$ \\
72 hours $(n=30)$ & $0.7836 \pm 0.005$ & $0.7966 \pm 0.011$ & $1.0822 \pm 0.008$ & $1.3624 \pm 0.026$ \\
168 hours $(n=30)$ & $1.0003 \pm 0.004$ & $1.26800 \pm 0.051$ & $1.67057 \pm 0.046$ & $1.88543 \pm 0.033$ \\
\hline
\end{tabular}


Table 2: Comparison of dimensional change measured among different materials and the master die by one-way ANOVA

\begin{tabular}{|c|c|c|c|c|c|c|}
\hline & & Sum of squares & $d f$ & Mean square & $F$ & Sig. \\
\hline \multirow[t]{2}{*}{1 hour } & Between groups & 3.479 & 3 & 1.160 & 10166.842 & $<0.001^{* *}$ \\
\hline & Within groups & 0.013 & 116 & 0.000 & & \\
\hline \multirow[t]{2}{*}{24 hours } & Between groups & 4.310 & 3 & 1.437 & 14970.527 & $<0.001^{* *}$ \\
\hline & Within groups & 0.011 & 116 & 0.000 & & \\
\hline \multirow[t]{2}{*}{48 hours } & Between groups & 5.984 & 3 & 1.995 & 12008.310 & $<0.001^{* *}$ \\
\hline & Within groups & 0.019 & 116 & 0.000 & & \\
\hline \multirow[t]{2}{*}{72 hours } & Between groups & 6.784 & 3 & 2.261 & 9830.088 & $<0.001^{* *}$ \\
\hline & Within groups & 0.027 & 116 & 0.000 & & \\
\hline \multirow[t]{2}{*}{168 hours } & Between groups & 14.203 & 3 & 4.734 & 3189.041 & $<0.001^{* *}$ \\
\hline & Within groups & 0.172 & 116 & 0.001 & & \\
\hline
\end{tabular}

$p$ denotes the level of significance, where if $p>0.05=$ not significant, $p<0.05=$ significant ${ }^{*}$, and $p<0.001=$ highly significant ${ }^{* *}$

shortcomings. Stability of interocclusal record is required primarily to allow mounting the casts on the articulator at a convenient time in a clinical setup or to accommodate the transportation time required in their transfer from a clinic to a laboratory. This transfer may be from a village to a town, or from a town to a city and in some cases even between different states or a country. Most clinicians, therefore, prefer an interocclusal record material that is dimensionally stable for several days, especially in recent times where frequent lockdowns due to the COVID-19 pandemic have made business very unpredictable for so many professions including dentistry. The main findings of this study were that none of the samples obtained from different recording materials were similar to the master die in linear dimensions, and among different materials, the PVS was more stable at all investigated parameters (1, 24, 48, 72, and 168 hours). Samples of Gp II (polyether) exhibited a greater dimensional change than Gp I (PVS) despite both being elastomers. The difference can be explained based on polyether being slightly hydrophilic in nature and may react to the moisture from the environment more as compared to the PVS. ${ }^{14}$ Low dimensional stability of Gp III (zinc oxide eugenol) with the passage of time, is due to its chelation reaction process which is a typical acid/base reaction in which one of the end products is water besides forming the key salts. ${ }^{15}$ The samples of the Gp IV (Aluwax) showed greatest linear changes, first hours linear change (mean $=$ 0.60 ) being almost equal to 48 hours linear change of PVS (mean = 0.66). The shrinkage of Aluwax has been attributed to the greater coefficient of thermal expansion and distortion to stress release. While early linear changes were more in Aluwax, at the end of 7 days the dimensional changes were, however, only slightly more than $\mathrm{ZnOE}$. Although several factors contribute to dimensional changes, the biggest factor that contributes is the loss of volatile substance over a period of time. ${ }^{14}$ This concurred with the results of the present study. A study conducted by Millstein and $\mathrm{Hsu}^{16}$ found a correlation between volatile loss (induced weight loss) and linear dimensions in IRMs. However, a study by Michalakis et al. ${ }^{17}$ found no such correlation. While changes can occur in multiplanes along with a sample, the changes that are vertical in nature affect occlusal vertical dimensions and the changes in horizontal plane affect mainly centric relation records. Polyvinyl siloxane has been reported by Dua et al. to exhibit less linear dimensional changes in the horizontal plane than polyether material. ${ }^{18}$ Our results of PVS being more dimensionally more stable than $\mathrm{ZnOE}$ and registration wax are also supported by similar studies. ${ }^{19-21}$
Dimensional stability also decreases as the time interval between recording and mounting increases. Müller et al. recommended that PVS interocclusal records must be articulated within 24 hours while $\mathrm{ZnOE}$ and wax records should be articulated within 1 hour to get accurate restoration. ${ }^{22}$ Our results, however, show that both Gp I (PVS) and Gp II (polyether) show their greatest dimensional changes in the first 24 hours after which the changes begin to slow down. Both materials are known for the shrinkage associated with their setting. In a study on eugenol-free zinc oxide interocclusal records and polyether-based interocclusal registration material, Balthazar-Hart et al. ${ }^{5}$ reported eugenol-free zinc oxide to be more stable dimensionally (more linear) than polyether-based materials, although polyether material has reported improved properties since then. Polyvinylsiloxane has also been shown to possess superior dimensional stability when the thickness of the interocclusal record is varied. ${ }^{21}$ Michalakis et al. ${ }^{17}$ studied the linear dimensional change of several elastomeric IRMs and observed that polyether (Ramitec) presented a smaller linear change at all time intervals than the addition silicones. Tejo et al. ${ }^{23}$ while comparing dimensional stability among three different interocclusal materials observed that polyether was most dimensionally stable followed by silicone and zinc oxide. However, a study by Gurav et al. ${ }^{24}$ concluded that $\mathrm{ZnOE}$ and polyether were more stable followed by silicone. These conclusions, however, are not in agreement with this study. The differences could be that the present study took only linear measurement as a parameter for studying dimensional stability, whereas, in routine clinical situations, dimensional errors occur in all three dimensions.

\section{Limitations of the Study}

The study does not take into account the effect of storage (disinfectant) on the material properties as some interocclusal record materials need to be stored in different recommended containers and conditions. The study also evaluated only linear dimensional changes which should be kept in consideration during the interpretation of our results.

\section{Conclusion}

All IRMs demonstrated linear dimensional changes at different time intervals. Polyvinylsiloxane is the material of choice for fixed restorations and while mounting the dental cast is deferred, followed by polyether. The ZnoE and Aluwax are the least desired except when used in removable prosthodontics. During the current 


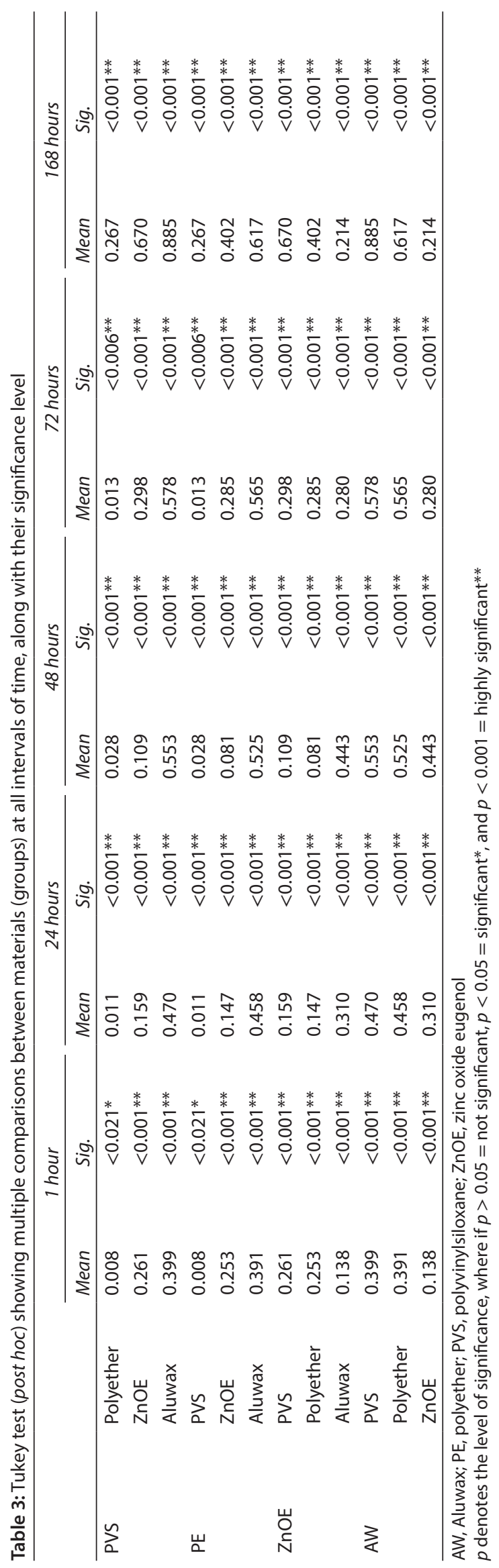

pandemic, every dentist should find a way to mount the patient's casts immediately after recording and should refrain from choosing an option where the mounting will be done after a few days.

\section{ACKnOWledgments}

The authors would like to acknowledge the efforts of the staff of the engineering college of the same university, the statistician and the dental technicians of the prosthodontic laboratory for their valued contribution in shaping this study. The authors would also like to raise the value of the students of the department of prosthodontics for their valued help.

\section{References}

1. Zarb GA, Bolender CL. Prosthodontic Treatment for Edentulous Patients. 12th ed., St. Louis, Philadelphia: Mosby; 2004. pp. 243-247.

2. Sathe S, Gufran K, Hamza MOB, et al. Success of immediate implants in anterior esthetic zone: one year prospective study. World J Dent 2018;9(6):451-456. DOI: 10.5005/jp-journals-10015-1579.

3. Ghazal M, Kern M. Mounting casts on an articulator using interocclusal records. J Prosthet Dent 2008;100(5):408-409. DOI: 10.1016/S00223913(08)60247-4.

4. Gounder R, Vikas BVJ. Comparison of disinfectants by immersion and spray atomization techniques on the linear dimensional stability of different interocclusal recording materials: an in vitro study. Eur J Dent 2016;10(1):7-15. DOI: 10.4103/1305-7456.175684.

5. Balthazar-Hart Y, Sandrik JL, Malone WF, et al. Accuracy and dimensional stability of four interocclusal recording materials. J Prosthet Dent 1981;45(6):586-591. DOI: 10.1016/0022-3913(81)904169.

6. Warren K, Capp N. A review of principles and techniques for making interocclusal records for mounting working casts. Int J Prosthodont 1990;3(4):341-348.

7. Phukela SS, Malhotra P, Setya G, et al. Comparison of adaptation of acrylic resin cured by injection molded technique or microwave energy: an in vitro study. World J Dent 2020;11(1):24-29. DOI: 10.5005/ jp-journals-10015-1690.

8. Abdallah RM, Aref NS. An in vitro assessment of physicomechanical properties of heat-cured denture base resin disinfected by ozonized water. World J Dent 2020;11(2):146-150. DOI: 10.5005/ jp-journals-10015-1718.

9. Guo H, Zhou Y, Liu X, et al. The impact of the COVID-19 epidemic on the utilization of emergency dental services. J Dent Sci 2020;15(4):564567. DOI: $10.1016 /$ j.jds.2020.02.002.

10. Freilich MA, Altieri JV, Wahle JJ. Principles for selecting interocclusal records for articulation of dentate and partially dentate casts. Prosthet Dent 1992;68(2):361-367. DOI: 10.1016/0022-3913(92)90346c.

11. World Medical Association. World Medical Association declaration of Helsinki: ethical principles for medical research involving human subjects. JAMA 2013;310(20):2191-2194. DOI: 10.1001/ jama.2013.281053.

12. Council on Dental Materials and Devices. Revised American Dental Association no. 19 for non-aqueous, elatomeric dental impression materials. J Am Dent Assoc 1977;94(4):733-741. DOI: 10.14219/jada. archive.1977.0334.

13. Chandu GS, Khan MF, Mishra SK, et al. Evaluation and comparison of resistance to compression of various interocclusal recording media: an in vitro study. J Int Oral Health 2015;7(5):24-29.

14. Craig RG, Peyton F. Impression Materials, Restorative Dental Materials. 5th ed., St. Louis, Philadelphia: Mosby; 1975. pp. 348-352.

15. Shikha G, Aman A, Anil S, et al. A comparative evaluation of linear dimensional change and compressive resistance of different interocclusal recording materials - an in vitro study. Indian J Dent Sci 2013;4:32-37. 
16. Millstein PL, Hsu CC. Differential accuracy of elastomeric recording materials and associated weight change. J Prosthet Dent 1994;71(4):400-403. DOI: 10.1016/0022-3913(94)90103-1.

17. Michalakis KX, Pissiotis A, Anastasiadou V, et al. An experimental study on particular physical properties of several interocclusal recording media. Part II: linear dimensional change and accompanying weight change. J Prosthodont 2004;13(3):150-159. DOI: 10.1111/j.1532849X.2004.04024.x.

18. Dua P, Gupta SH, Ramachandran S, et al. Evaluation of four elastomeric interocclusal recording materials. Med J Armed Forces India 2007;63(3):237-240. DOI: 10.1016/S0377-1237(07) 80143-2.

19. Anup G, Ahila SC, Vasanthakumar M. Evaluation of dimensional stability, accuracy and surface hardness of interocclusal recording materials at various time intervals: an in vitro study. J Indian Prosthodont Soc 2011;11(1):26-31. DOI: 10.1007/s13191-0110054-0.
20. Arya S, Nagar P. Comparative evaluation of the accuracy and dimensional stability of three interocclusal recording materials - an in vitro study. IJARESM 2016;4(1):4-9.

21. Gupta S, Arora A, Sharma A, et al. Comparative evaluation of linear dimensional change and compressive resistance of different interocclusal recording materials - an in vitro study. Indian J Dent Sci 2013;5:32-37.

22. Müller J, Götz G, Hörz W, et al. Study of the accuracy of different recording materials. J Prosthet Dent 1990;63(1):41-46. DOI: 10.1016/0022-3913(90)90263-c.

23. Tejo SK, Kumar AG, Kattimani VS, et al. A comparative evaluation of dimensional stability of three types of interocclusal recording materials - an in-vitro multi-centre study. Head Face Med 2012;8(1):27. DOI: 10.1186/1746-160X-8-27.

24. Gurav SV, Khanna TS, Nandeeshwar DB. Comparison of the accuracy and dimensional stability of interocclusal recording materials - an in vitro study. Int J Sci Res Publ 2015;5:2250-3153. 